\title{
Electrophysiological Evidence for Both Perceptual and Postperceptual Selection during the Attentional Blink
}

\author{
Barry Giesbrecht, Jocelyn L. Sy, and James C. Elliott
}

\begin{abstract}
When two masked targets are presented in rapid succession, correct identification of the first target (T1) leads to a dramatic impairment in identification of the second target (T2). Several studies of this so-called attentional blink (AB) phenomenon have provided behavioral and physiological evidence that T2 is processed to the semantic level, despite the profound impairment in T2 report. These findings have been interpreted as an example of perception without awareness and have been explained by models that assume that $\mathrm{T} 2$ is processed extensively even though it does not gain access into consciousness. The present study reports two experiments that test this assumption. In Experiment 1, the perceptual load of the T1 task was manipulated and T2 was a word that was either related or
\end{abstract}

\section{INTRODUCTION}

Visual scenes contain more information than can be consciously perceived at any given point in time. Attention provides a powerful cognitive coping mechanism that mediates the selective processing of a subset of the information that is consistent with our current behavioral goals. The benefits of selective attention have been well characterized in terms of improved behavioral performance and enhanced neural activity evoked in response to attended stimuli (e.g., Heinze et al., 1994; Mangun \& Hillyard, 1991; Corbetta, Miezin, Dobmeyer, Shulman, \& Petersen, 1990; Posner, 1980; Van Voorhis \& Hillyard, 1977; Hillyard, Hink, Schwent, \& Picton, 1973). However, the benefits resulting from this selectivity come at a cost. For example, when two masked targets are presented in a rapid sequence, identification of the first target (T1) hinders the identification of the second target (T2) for about 500 msec. The transient impairment in report is thought to reflect a processing limitation that renders T2 unattended and it is known as the attentional blink (AB; Raymond, Shapiro, \& Arnell, 1992).

Despite the profound deficit in conscious report, numerous studies have provided behavioral and physiological evidence that $\mathrm{T} 2$ is processed extensively during

University of California, Santa Barbara unrelated to a context word presented at the beginning of each trial. The event-related potential (ERP) technique was used to isolate the context-sensitive N400 component evoked by the T2 word. The ERP data revealed that there was a complete suppression of the $\mathrm{N} 400$ during the $\mathrm{AB}$ when the perceptual load was high, but not when perceptual load was low. Experiment 2 replicated the high-load condition of Experiment 1 while ruling out two alternative explanations for the reduction of the N400 during the AB. The results of both experiments demonstrate that word meanings are not always accessed during the $\mathrm{AB}$ and are consistent with studies that suggest that attention can act to select information at multiple stages of processing depending on concurrent task demands. the $\mathrm{AB}$. The first published report that information presented during the $\mathrm{AB}$ is processed extensively used the event-related potential (ERP) technique to measure the magnitude of the N400 component evoked by T2 words (Luck, Vogel, \& Shapiro, 1996). The N400 component is measured as a large negative deflection in the ERP occurring approximately $400 \mathrm{msec}$ after the presentation of a stimulus that does not match an established semantic context (Kutas \& Hillyard, 1980). For example, the N400 measured in response to the word "NURSE" would be more robust if the word had been preceded by the word "HORSE" relative to if "NURSE" had been preceded by the word "DOCTOR." Luck et al. (1996) used the amplitude of the N400 component to index the extent to which $\mathrm{T} 2$ is processed to a semantic level during the $\mathrm{AB}$. To establish the semantic context, Luck et al. started each trial with the presentation of a context word (e.g., "DOCTOR" or "HORSE") and then presented subjects with rapid sequence of stimuli within which there were two targets. Critically, the second target word (e.g., "NURSE") was either semantically related (e.g., the context word was "DOCTOR") or unrelated (e.g., the context word was "HORSE") to the context word. Luck et al. found that the size of the N400 for words presented during the $\mathrm{AB}$ was as large as the $\mathrm{N} 400$ for words presented outside the AB. Luck et al. reasoned that because the $\mathrm{N} 400$ reflects the result of a comparison 
between current semantic representations with a previously established context (e.g., Kutas \& Hillyard, 1980), the presence of the $\mathrm{N} 400$ during the $\mathrm{AB}$ indicates that although the T2 word could not be reported, it was processed to the postperceptual level (i.e., fully identified) and compared to the context established by the word presented at the beginning of the trial (see also Vogel, Luck, \& Shapiro, 1998).

Subsequent to Luck et al.'s (1996) original report that T2 is processed to a semantic level, there has been a remarkable degree of convergent evidence published in the literature further demonstrating that information is extensively processed during the AB. Behavioral studies, for instance, have shown that $\mathrm{T} 2$ can prime a response to a third target presented outside the $\mathrm{AB}$, independent of the accuracy of the T2 response (Shapiro, Driver, Ward, \& Sorensen, 1997). Evidence for semantic processing during the $\mathrm{AB}$ has also been provided by studies showing that high priority stimuli, such as personal names or happy faces, are not subject to the deficit in report (Mack, Pappas, Silverman, \& Gay, 2002; Shapiro, Caldwell, \& Sorensen, 1997). Extensive processing during the $\mathrm{AB}$ is not restricted to target items because Maki, Frigen, and Paulson (1997) found that if the items presented immediately before $\mathrm{T} 2$ are associatively related to $\mathrm{T} 2$, then there is a reduction in the $\mathrm{AB}$. Interestingly, there is also evidence that semantic relationships between T1 and T2 not only benefit T2 accuracy but also result in an increase of $\mathrm{T} 1$ accuracy if $\mathrm{T} 2$ is presented within 50 msec of T1 (Potter et al., 2005). Physiological studies have extended Luck et al.'s by showing that the $\mathrm{N} 400$ is present during the $\mathrm{AB}$, both when $\mathrm{T} 2$ is correctly reported and when it is not (Rolke, Heil, Streb, \& Henninghausen, 2001). Moreover, there is also preserved sensory processing as indexed by visual P1 and N1 ERP components (Sergent, Baillet, \& Dehaene, 2005; Vogel et al., 1998) and categorical processing as indexed by the responses of category selective visual areas measured with functional magnetic resonance imaging (Marois, Yi, \& Chun, 2004).

Preserved semantic processing during the $\mathrm{AB}$ has been interpreted within the context of a variety of models. Each model differs with respect to the nature of the processing limitation that causes the deficit in report. For instance, traditional accounts of the $\mathrm{AB}$ explain the deficit in $\mathrm{T} 2$ report as a capacity or resource limitation caused by attending to T1 (Marois et al., 2004; Jolicoeur, 1999; Vogel et al., 1998; Chun \& Potter, 1995; Raymond, Shapiro, \& Arnell, 1995; Duncan, Ward, \& Shapiro, 1994; Shapiro, Raymond, \& Arnell, 1994). If T2 is presented during the period when resources are allocated to $\mathrm{T} 1$, the encoding of $\mathrm{T} 2$ is delayed and, during this period of delay, it is vulnerable to interference (Giesbrecht \& Di Lollo, 1998). More recent models have explained the $\mathrm{AB}$ not as a resource limitation but rather as a failure in configuring the information processing system for processing the second target (Di Lollo,
Kawahara, Shahab Ghorashi, \& Enns, 2005), a failure in the creation of object-level representations (Raymond, 2003), or a generalized selection failure (Olivers \& Watson, 2006). Despite the fundamental differences in terms of the nature of the processing limitation that causes the $A B$, all models explain semantic processing during the $\mathrm{AB}$ by appealing to classic late selection models of attention that propose that potential target items are analyzed to a postperceptual level without limitation prior to consolidation into a durable form for report (e.g., Deutsch \& Deutsch, 1963). According to this common assumption, whether the $\mathrm{AB}$ is due to a resource limitation, a failure in configuration, or generalized selection failure, the second target is processed to the level of meaning even though it cannot be reported.

\section{The Present Study}

Although the evidence is clear that T2 can be processed to the postperceptual level during the $\mathrm{AB}$, based on the broader selective attention literature, an argument can be made that extensive processing of T2 may not always occur. Indeed, several studies of spatial attention have shown that in a flanker task, if the target task is high in perceptual load, then task-irrelevant distractors show reduced interference on response times to the target and evoke a reduced visual P1 ERP relative to when the target task is low in perceptual load (e.g., Handy, Soltani, \& Mangun, 2001; Lavie, 1995; Lavie \& Tsal, 1994). In a similar vein, functional magnetic resonance imaging studies have shown that activity in motionselective area MT (middle temporal) evoked in response to task-irrelevant motion and activity in the amygdala evoked in response to task-irrelevant emotional faces is reduced when the primary task is difficult (Pessoa, McKenna, Guitierrez, \& Ungerleider, 2002; Rees, Frith, \& Lavie, 1997). These findings have been explained within the context of models that propose that attention acts to select information at multiple stages of processing (Lavie, 2005; Vogel, Woodman, \& Luck, 2005; Lavie, Hirst, de Fockert, \& Viding, 2004; Lavie \& Tsal, 1994). According to one model, the stage at which attention operates to filter information depends on task load. This so-called "load theory" is based on the assumption that the perceptual system has a pool of resources that is always committed in full to processing available information (Lavie, 2005; Lavie et al., 2004; Lavie \& Tsal, 1994). Critically, the demand, or load, placed on the perceptual system by processing of the task-relevant information determines the extent to which task-irrelevant information is processed. Under conditions of low load, all resources are not required for processing the taskrelevant information, thus uncommitted resources "spillover" to the perceptual processing of task-irrelevant information. In contrast, under conditions of high load, all resources are devoted to the task-relevant information, leaving no spare capacity for perceptual processing 
of task-irrelevant information, and thus, reducing the extent to which this extraneous information is processed beyond the perceptual level. In sum, load theory effectively predicts that under conditions of low load, attention selects information at relatively later stages of processing, whereas under conditions of high load, attention selects information at earlier stages of processing. Thus, based on load theory, extensive processing of $\mathrm{T} 2$ during the $\mathrm{AB}$ should be constrained by perceptual load.

In the present study, we tested whether semantic processing of T2 is constrained by load. A straightforward application of load theory to the $\mathrm{AB}$ makes the following prediction: T2 should be processed extensively under conditions of low perceptual load, but not under conditions of high perceptual load. To test this hypothesis, we revisited Luck et al.'s (1996) finding that the AB does not modulate semantic processing. Like Luck et al., the ERP technique was used to measure the N400 evoked by $\mathrm{T} 2$ words presented during the $\mathrm{AB}$. To test the influence of task load on the magnitude of the N400 evoked by $\mathrm{T} 2$, we manipulated the difficulty of the first target (T1) task. That rationale for manipulating T1-load rather than T2-load was based on the finding that the magnitude of the N400 is modulated by data-limiting stimulus manipulations (e.g., perceptual degradation by visual noise; Vogel et al., 1998), therefore, we wanted to avoid any manipulation of load that could be explained as a mere data limitation. Moreover, manipulating the load of the T1 task rather than the T2 task ensured that the T2 stimulus was the same regardless of load, thus any differences in the magnitude of the T2-evoked $\mathrm{N} 400$ as a function of load cannot be due to a stimulus confound between the load conditions. We report two experiments using this basic empirical approach and, consistent with the load hypothesis, the results indicate that semantic processing of $\mathrm{T} 2$ words presented during the $\mathrm{AB}$ can proceed unconstrained under conditions of low load, but that under conditions of high load, semantic processing of $\mathrm{T} 2$ during the $\mathrm{AB}$ was reduced, and sometimes completely absent.

\section{EXPERIMENT 1}

There were two key manipulations in Experiment 1. First, T1-load was manipulated using a flanker task in which participants made an unspeeded discrimination about a briefly presented masked stimulus that consisted of a single arrow flanked by pairs of arrows pointing either in the same direction (congruent, e.g., $>>>>>$ ) or in different directions (incongruent, e.g., $<<><<$ ). Because a long line of studies have demonstrated that performance is better when the target and flankers are congruent than when they are incongruent (Eriksen \& Eriksen, 1974), these conditions will be referred to as low- and high-load conditions, respectively. Second, T2 words were either related or unrelated to a context word presented at the beginning of each trial. We recorded each subjects' electroencephalogram (EEG) while he or she performed the task. From the EEG we quantified the magnitude of the context-sensitive N400 ERP (e.g., Kutas \& Hillyard, 1980) by computing the unrelated - related difference wave and then computing the mean amplitude over the 300-500 msec poststimulus time window (Vogel et al., 1998; Luck et al., 1996). If semantic processing of T2 is not constrained by concurrent attentional demands imposed by the T1 task, then an N400 should be observed in all conditions. However, if task load modulates the extent to which semantic processing occurs, then the magnitude of the N400 should be reduced during the $\mathrm{AB}$ under conditions of high load.

\section{Methods}

\section{Participants}

Twelve undergraduates from the University of California, Santa Barbara were paid $\$ 10$ /hour for their participation (mean age $=19 ; 9$ women).

\section{Apparatus and Stimuli}

Stimulus presentation was controlled using custom scripts written for MATLAB (Mathworks, Boston, MA) using the functions provided by the Psychophysics Toolbox (Brainard, 1997). T1 stimuli were black and consisted of a central arrow $\left(0.4^{\circ} \times 0.4^{\circ}\right)$ centered between two pairs of arrows $\left(0.4^{\circ} \times 1.1^{\circ}\right)$. The distance between adjacent arrows was $0.15^{\circ}$. The complete target stimulus subtended $0.4^{\circ} \times 2.6^{\circ}$. The context word presented at the beginning of the trial and the T2 word were black and white, respectively. Both were presented in uppercase 32-point Arial font. Each character subtended approximately $0.4^{\circ} \times 0.4^{\circ}$. T1 and T2 masks were strings of black numbers and uppercase letters the same length as the respective target. All stimuli were presented on a neutral gray background and viewed on a 19-in. color monitor from a distance of $125 \mathrm{~cm}$.

\section{Procedure}

Each trial began with a random fixation interval (500$1000 \mathrm{msec}$ ), followed by the context word (1000 msec). After the context word there was a second random delay (750-1250 msec) and then T1 and the T1 mask were presented $($ duration $=53.3 \mathrm{msec}$; T1-mask ISI $=53.3 \mathrm{msec}$ ) After the lapse of the temporal lag for that trial, T2 was presented (40 msec) and then masked (40 msec; T2-mask ISI $=40 \mathrm{msec}){ }^{1}$ After a third random delay (750-1250 msec), subjects were prompted to indicate their responses for $\mathrm{T} 1$ and $\mathrm{T} 2$. Subjects were instructed to read the context word presented at the beginning of the trial. At the end of the trial they were to indicate the 
direction of the central arrow (left or right) and whether T2 was related or unrelated to the context word. All responses were unspeeded and typed into the keyboard. After the responses were recorded, the fixation cross returned to the screen, and the participant started the next trial when ready. A sample trial sequence is shown in Figure 1.

\section{Design}

There were three independent variables: T1-load, T2relationship, and T1-T2 lag. T1-load was manipulated by the direction of the flankers relative to the central arrow and was either low (i.e., $>>>>>$ or $<<<<<$ ) or high (i.e., $<<><<$ or $>><>>$ ). T2-relationship specified the semantic association between T2 and the context word and was either related or unrelated. The specific words were compiled from previously published studies and norms (Giesbrecht, Camblin, \& Swaab, 2004; Postman \& Keppel, 1970) and consisted of 300 related word pairs. Each word pair was randomly assigned to each of the load conditions, under the constraint that across subjects each pair was assigned to each of the load conditions an equal number of times. Unrelated word lists were created by randomly shuffling the related word pairs (e.g., Vogel et al., 1998). T1-T2 lag was the temporal interval between the onsets of $\mathrm{T} 1$ and $\mathrm{T} 2$ and it was either 320 or $920 \mathrm{msec}$. The T1-load conditions were presented in separate blocks of trials, the order of which was counterbalanced across subjects. T2-relationship and T1-T2 lag conditions were randomly intermixed within each block. The T1-load conditions were blocked primarily so that the low-load condition of the present experiment was as similar to the experiment reported by Luck et al. (1996; see also Vogel et al., 1998), but also because previous studies of the $\mathrm{AB}$ have shown that randomly intermixing trials with varying levels of difficulty can bias subjects to assume that all trials will be difficult, which may influence the magnitude of the N400 on low-load trials (Shore, McLaughlin, \& Klein,
2001). There were 600 total trials (75 trials in each condition) that were divided in to 10 blocks ( 5 for each load condition) of 60 trials. Prior to the experimental trials, subjects were given 10 practice trials.

\section{Recording and Analysis}

EEG activity was recorded at $256 \mathrm{~Hz}$ from $32 \mathrm{Ag} / \mathrm{AgCl}$ sintered electrodes mounted in an elastic cap and placed according to the International 10/20 System. The horizontal and vertical electrooculograms (EOG) were recorded from electrodes placed $1 \mathrm{~cm}$ lateral to the external canthi (left and right) and above and below each eye, respectively. The data were re-referenced off-line to the average of the signal recorded from electrodes placed on the left and right mastoids and then band-pass filtered (0.1-30 Hz). Trials containing ocular artifacts (blinks and eye movements) detected by EOG amplitudes exceeding $\pm 50 \mu \mathrm{V}$ or by visual inspection were excluded from the analysis. The average percentage of trials that were rejected was 6.9\% (range: 1.3-15.2\%).

The average ERP waveforms in all conditions were computed time-locked to the onset of T2 and included a 200-msec prestimulus baseline and a 600-msec poststimulus interval. The N400 was isolated by subtracting the resulting ERP waveforms on related trials from the ERP waveforms on unrelated trials. It is important to note that for a given subject, lag, and load condition the T2 word was exactly the same (only context word was different), therefore, any modulations observed in the resulting difference wave cannot be attributed to physical stimulus differences. The magnitude of the N400 was quantified as the mean amplitude of the difference waves over the 300-500 msec post-T2 time window. N400 measurements were obtained from frontal, central, and parietal electrodes (Vogel et al., 1998; Luck et al., 1996). As with previous studies, the mean amplitudes included both T2 correct and T2 incorrect trials (Vogel et al., 1998; Luck et al., 1996). The inclusion of both correct and incorrect trials should increase the likelihood that an

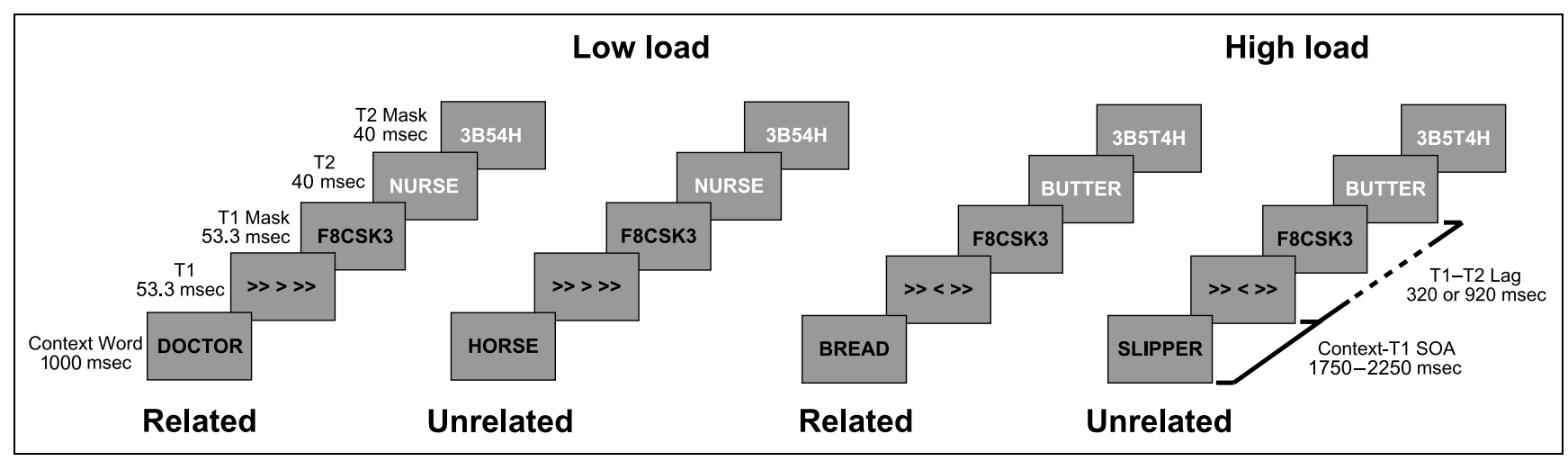

Figure 1. A schematic representation of the trial sequences used in Experiment 1. On the left are examples of T1-low load trials when the context word and T2 word were related and unrelated. On the right are examples of T1-high load trials when the context word and T2 word were related and unrelated. For complete details on the stimulus timing, see Methods. 
N400 will be observed during the $\mathrm{AB}$ because semantic access is more likely to occur on T2 correct trials. Thus, any observed reduction in the magnitude of the N400 during the $\mathrm{AB}$ is likely to be an underestimate of the true reduction of semantic processing. Unless mentioned otherwise, within-subjects analyses of variance (ANOVAs) were used for all statistical analyses, and the $p$ values were adjusted in accordance with the Greenhouse-Geisser epsilon value.

\section{Results and Discussion}

\section{Behavioral Data}

Overall mean percentage of correct T1 responses was 94.3\%. As expected, the load manipulation impacted performance, such that participants were accurate on 98.1\% of the trials in the low-load condition compared to $90.6 \%$ of the trials in the high-load condition $[t(11)=$ $2.75, p<.02$, SEM $=2.72]$.

Mean percentage of correct T2 responses ${ }^{2}$ is plotted as a function of T1-load and lag in Figure 2A. As with T1 accuracy, T2 accuracy was lower when T1-load was high than when T1-load was low $[79.8 \%$ vs. $83.1 \%, F(1,11)=$ $\left.6.52, p<.03, \eta^{2}=0.372\right]$. Accuracy was $76.8 \%$ when T2 was presented at the $320-\mathrm{msec}$ lag and it improved to $86.1 \%$ when T2 was presented at the 920-msec lag. This main effect of lag was statistically significant $[F(1,11)=$ 27.63, $\left.p<.001, \eta^{2}=0.72\right]$ and is indicative of a significant $\mathrm{AB}$. The lag effect changed as a function of T1-load, such that the AB was more severe when T1-load was high than when T1-load was low $[F(1,11)=4.94$, $\left.p<.05, \eta^{2}=0.31\right]$.

\section{ERP Data}

The ERP results are summarized in Figure $2 \mathrm{~B}$ and Figure 3. Figure 2B depicts the mean N400 amplitude plotted as a function of T1-load and T1-T2 lag. Figure 3 shows the difference waveforms for midline frontal, central, and parietal electrode sites as a function of load and lag. The mean amplitudes were entered into a repeated measures ANOVA that included T1-load, T1-T2 lag, anterior-posterior electrode position (frontal, central, parietal), and left-right electrode position (left, midline, right). Overall, the N400 was larger over midline and right hemisphere electrode locations compared to left hemisphere electrode locations $[F(2,22)=7.28$, $\left.p<.005, \eta^{2}=0.398\right)$. There was a significant main effect of lag on N400 amplitude, such that, overall, the magnitude of the N400 was smaller (i.e., less negative) at the 320 -msec lag than at the 920-msec lag $[F(1,11)=15.52$, $\left.p<.002, \eta^{2}=0.585\right]$. As predicted, there was an interaction between T1-load and lag $[F(1,11)=23.74$, $\left.p<.001, \eta^{2}=0.683\right]$, such that when load was low, the magnitude of the N400 was not affected by lag, but when load was high, the magnitude of the N400 at the 320-msec lag was reduced. Separate planned $t$ tests revealed that the magnitude of the N400 during the $\mathrm{AB}$ was significantly different than zero in the low-load condition $[t(11)=5.69, p<.001]$, but not in the high load condition $[t(11)=0.37, p>.70]$.

The interaction between T1-load and T1-T2 lag revealed in the statistical analysis of the N400 amplitude data is apparent on visual inspection of the difference waveforms shown in Figure 3. Consistent with the N400's typical characteristics (Kutas \& Hillyard, 1980),
Figure 2. Results of Experiment 1. (A) Mean percentage of correct $\mathrm{T} 2$ responses as a function of T1-load (low or high) and T1-T2 lag (320 or $920 \mathrm{msec}$ ). (B) Mean amplitude of the N400 plotted as a function of T1-load and T1-T2 lag. In this and subsequent figures, mean amplitude measurements were based on the mean voltage of the unrelated - related difference wave over the 300-500 msec post-T2 time window. The amplitudes shown in the figure are those that produced the significant Load $\times$ Lag interaction (see text), averaged across all electrode sites included in the analysis. Error bars in this and subsequent figures represent the standard error of the mean appropriate for within-subjects comparisons (Loftus \& Masson, 1994).

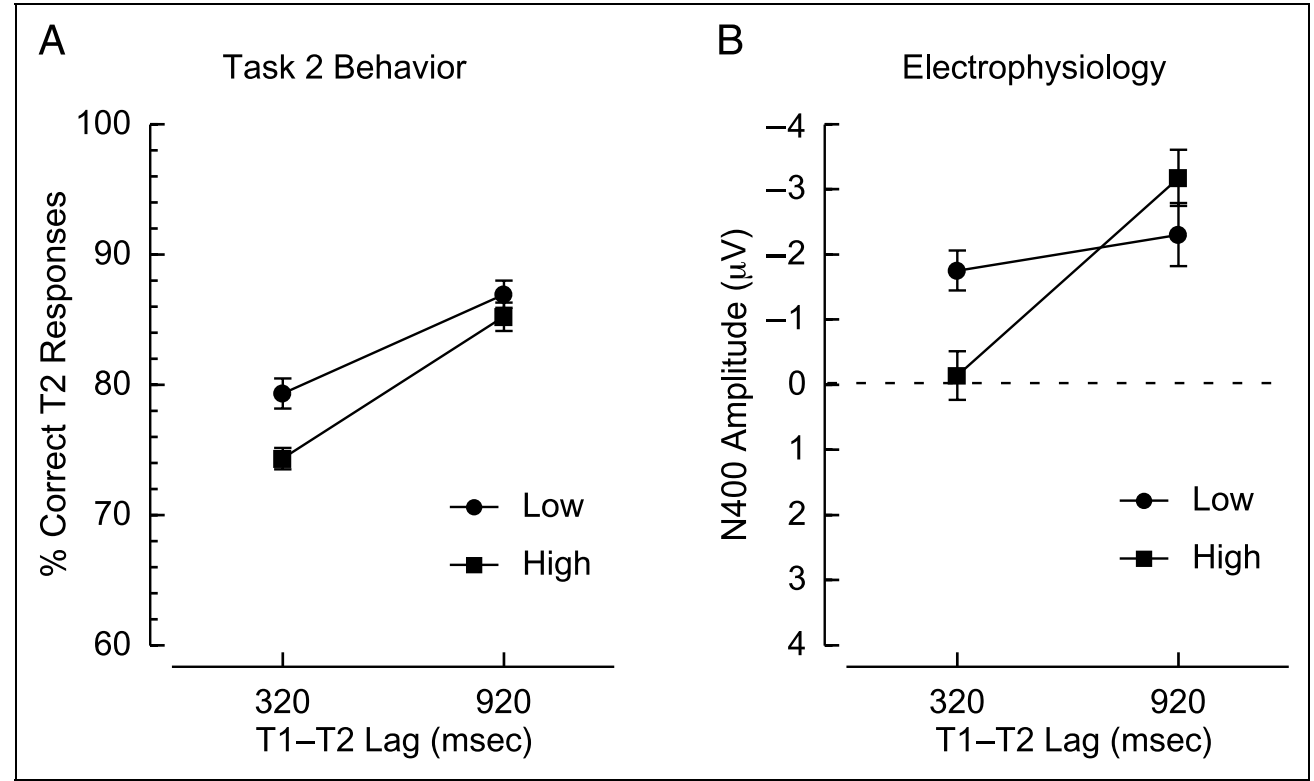


Figure 3. Average ERP unrelated - related difference waveforms at frontal (Fz), central $(\mathrm{Cz})$, and parietal $(\mathrm{Pz})$ electrode sites. The top row are the difference waves when T1-load was low and the bottom row are the difference waves when T1-load was high. Solid traces are from trials in which $\mathrm{T} 2$ was presented 920 msec after T1 and dotted traces are from trials in which $\mathrm{T} 2$ was presented $320 \mathrm{msec}$ after T1 (i.e., during the $\mathrm{AB}$ ). By convention negative is plotted upward. Time zero is when T2 onset occurred. For display purposes only, the waveforms in this and subsequent figures were convolved with a Gaussian impulse response function with a standard deviation of $6 \mathrm{msec}$ and half-amplitude cutoff of $30 \mathrm{~Hz}$.

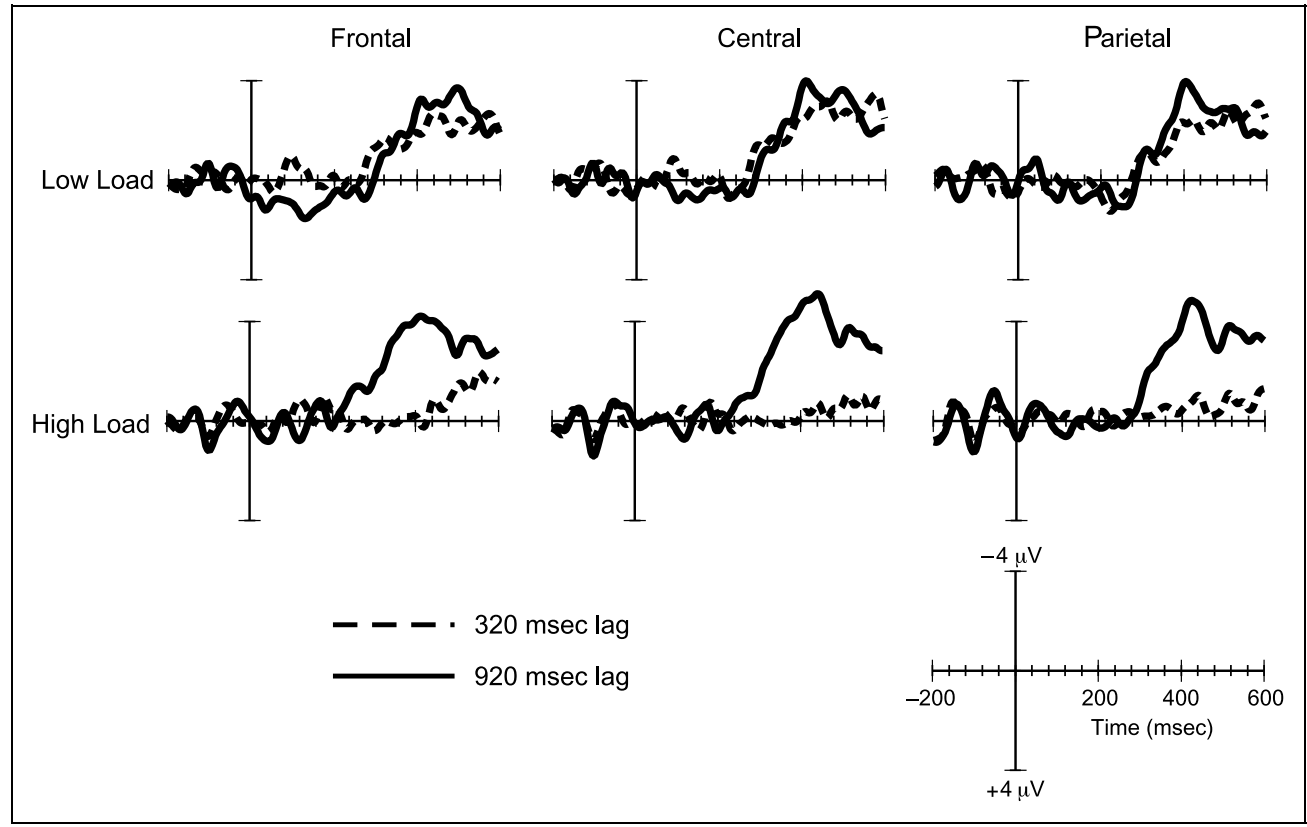

the primary component was a negative peak at around 400 msec. Under conditions of low load (top row), the difference waveforms for the 320-msec and 920-msec lag conditions overlap. This pattern is consistent with Luck et al.'s (1996) finding that the AB does not modulate the N400. In contrast, the difference waveforms in the highload condition do not: When T2 was presented 920 msec after $\mathrm{T} 1$, there was a large negative deflection, but when T2 was presented during the $\mathrm{AB}$ (320 msec lag), the difference waveform was at or near zero throughout the epoch.

The observed modulation of the N400 by the interaction between T1-load and lag is consistent with the hypothesis that concurrent task demands can constrain access to word meaning. However, there are three important caveats regarding the support for this hypothesis provided by the results of Experiment 1. First, previous studies have shown that the N400 is sensitive to perceptual degradation (Vogel et al., 1998), thus it could be argued that the reduction in the modulation of the N400 observed represents a data limitation and not a failure of selective attention. It is unlikely that this alternative can account for the present results because the modulation of the N400 in the high-load condition was observed in the unrelated - related difference waveforms derived from a paradigm in which the critical stimulus (T2) was the same in all conditions. Second, it could be argued that the reduced N400 in the high-load condition arose because of an artifact of presenting the load conditions in different blocks of trials rather than mixed within blocks. We conducted a follow-up study that was exactly the same as that reported here, except the load conditions were randomly intermixed and, again, we found a complete suppression of the N400 during the $\mathrm{AB}$ under conditions of high T1-load (Giesbrecht \& Sy, 2006). Thus, it is unlikely that subject strategies engendered by the blocked load manipulation alone caused the reduction of the magnitude of the N400 in the high-load condition of the present experiment. Third, although the statistical analysis revealed that the magnitude of the N400 was not significantly different than zero during the $\mathrm{AB}$ in the high-load condition, it is possible that semantic processing did occur, but our statistical analyses were not sensitive to this processing. Indeed, there is some indication of a negative deflection occurring at about $400 \mathrm{msec}$ in the high-load, $320 \mathrm{msec}$ lag condition at the frontal electrode location (bottom left of Figure 3), suggesting that the N400 might be present, but delayed in the high-load condition. Additional analyses were performed based on time windows extending beyond the 300-500 msec time window reported here. These subsequent analyses again revealed a significant interaction between difficulty and lag, consistent with the analyses reported here. Moreover, although there was a suppression of the N400 in the present experiment, the suppression does not need to be complete to provide support for the present hypothesis.

The results of the low-load condition, where $\mathrm{AB}$ did not modulate the magnitude of the N400, are consistent with previous electrophysiological studies showing that meaning can survive the AB (e.g., Rolke et al., 2001; Luck et al., 1996). The results of the high-load condition, however, are not consistent with previous studies and challenge models of the $\mathrm{AB}$ that assume that $\mathrm{T} 2$ is processed to the level of meaning without limitation. Indeed, the complete suppression of the N400 at the 
320-msec lag in the high-load condition suggests that, under conditions of high-load, T2 word meaning was not accessed during the $\mathrm{AB}$.

\section{EXPERIMENT 2}

In Experiment 2, the T1 task was changed to address two issues. The first issue pertains to the possibility that the reduced $\mathrm{N} 400$ during the $\mathrm{AB}$ in the high-load condition of Experiment 1 was caused by subjects restricting their focus of spatial attention tightly on the location of the central arrow for the duration of the trial. Although zooming of spatial attention would facilitate exclusion of the distracting flankers in the T1 stimulus (e.g., Eriksen \& St. James, 1986), if the restricted focus was still in place when T2 was presented, then much of the word would fall outside the "spotlight" of attention. This is potentially problematic because previous studies have shown that presenting words at unattended spatial locations reduces the magnitude of the N400 (McCarthy \& Nobre, 1993), thus, if the attentional "spotlight" did not encompass most of the T2 word, then it would not be surprising to find a reduced N400 under conditions of high load. The second issue pertains to the source of interference caused by the distractors. Specifically, interference in the flanker task can arise from (a) response conflict from distractors that map onto a competing response and (b) perceptual conflict due to distractors that are visually similar to the target (Eriksen \& Eriksen, 1974; Eriksen \& Hoffman, 1973). In Experiment 1, the distractors in the high-load condition were visually similar to the target and were mapped onto a competing response. Although the use of an unspeeded task and masked display likely emphasized interference caused by perceptual load, it is possible that the reduced N400 observed in the high-load condition of Experiment 1 was due to either perceptual load, response conflict, or some combination of the two sources of interference. Although a reduction in the $\mathrm{N} 400$ during the $\mathrm{AB}$ is interesting whether it is caused by perceptual or response load, the purpose of Experiment 2 was to more completely isolate the source of load.

To address these issues, two changes were made to the T1 task. First and foremost, subjects were required to indicate whether the outermost arrows of the stimulus were pointing in the same direction or in different directions. Second, the distractors presented between the outer arrows were either arrows pointing to the left or right or equals signs ("="). These changes address the issues in the following manner. With respect to the alternative explanation that the modulation of the N400 was due to subjects zooming their attention tightly on the location of the target arrow, changing the task to a discrimination of the outer arrows should discourage subjects from adopting this strategy. Indeed, for the subjects to perform the new task effectively, they could not just attend to a single character location, but rather they needed to attend to more of the T1 stimulus to make the discrimination. Thus, if the modulation of the N400 observed in the high-load condition of Experiment 1 was due to a zooming of attention, neither the arrows nor the equals condition should provide evidence for a reduced $\mathrm{N} 400$ during the $\mathrm{AB}$. With respect to whether the source of interference is perceptual or response related, the distractors in the "arrows" condition mapped onto potential responses, similar to the high-load condition of Experiment 1, which may have contained both perceptual and response conflict. However, the distractors in the "equals" condition did not map onto a potential response, thus there should be no response conflict. Although the visual similarity between the targets and the distractors in the arrows condition, which is higher than in the equals condition, will likely make the arrows task more difficult, it is important to note, however, that according to load theory, the "arrows" and "equals" conditions are similar in terms of their perceptual load. This is because according to load theory, one of the key factors that determines perceptual load is the number of items that needs to be identified to perform a task (Lavie, 2005; Lavie et al., 2004), which in the case of both the arrows and equals conditions, is two (i.e., the outermost arrows). Thus, if the modulation of the N400 during the AB in Experiment 1 was due to response conflict, then in Experiment 2 there should be a similar modulation of the N400 in the "arrows" condition, but not in the "equals" condition. If, however, the results in the previous experiment were due to the intended manipulation of perceptual load, then there should be a modulation of the N400 during the $\mathrm{AB}$ in both "arrows" and "equals" conditions.

\section{Methods}

Participants

Twelve undergraduates from the University of California, Santa Barbara participated for class credit (mean age $=$ 19.8; 7 women).

\section{Equipment, Stimuli, Design, Recording, and Analysis}

All aspects of this experiment were the same as the highload condition of Experiment 1 except that the distractors in the $\mathrm{T} 1$ stimulus were either three arrows pointing to the left or right (randomly determined) or three equals signs. The task of the subject was to indicate whether the two outer arrows were pointing in the same direction (e.g., " $><><>$ " or " $>===>$ ") or in different directions (e.g., " $<><>>$ " or " $<==$ $>$ "). The distractor conditions were presented in different blocks of trials, the order of which was counterbalanced across subjects.

Two participants were excluded from the analysis because of chance-level T1 accuracy. The remaining 
10 participants were included in all analyses. Trials containing ocular artifacts (blinks and eye movements) detected by EOG amplitudes exceeding $\pm 50 \mu \mathrm{V}$ or by visual inspection were excluded from the analysis. The average percentage of trials that were rejected was $7.5 \%$ (range: 1-27.8\%).

\section{Results and Discussion}

\section{Behavioral Data}

Mean percentage correct T1 responses was $80.2 \%$. There was a significant difference between the "arrows" and "equals" conditions, with accuracy being $71.9 \%$ in the arrows condition and $88.5 \%$ in the equals condition $[t(9)=$ $4.75, p<.001, S E M=2.93]$. Mean percentage of correct $\mathrm{T} 2$ responses is shown in Figure $4 \mathrm{~A}$ as a function of distractor type and T1-T2 lag. The only statistically significant effect was that of lag, such that accuracy was lower at the short lag than at the long lag, indicative of the presence of the $\mathrm{AB}\left[F(1,9)=42.83, p<.001, \eta^{2}=0.826\right]$.

\section{ERP Data}

The magnitude of the N400 is shown in Figure 4B. The mean amplitudes were entered into a repeated measures ANOVA that included anterior-posterior electrode position, left-right electrode position, T1-distractor type, and lag. The only significant effect of electrode position was the main effect of left-right location, which was driven by larger N400 amplitudes at midline and right hemisphere electrode sites than at left hemisphere sites $\left[F(2,18)=5.21, p<.02, \eta^{2}=0.366\right]$. Most importantly, there was a significant effect of lag, such that the magnitude of the $\mathrm{N} 400$ was smallest at the short lag $\left[F(1,9)=18.92, p<.002, \eta^{2}=0.678\right]$. Neither the effect of distractor type $[F(1,9)=1.09, p>.35$, $\left.\eta^{2}=0.108\right]$ nor the Distractor type $\times$ Lag interaction
$\left[F(1,9)=1.39, p>.25, \eta^{2}=0.134\right]$ was statistically significant. The difference waves recorded at frontal, central, and parietal locations are shown in Figure 5 and clearly reveal the effect of lag for both distractor types. Indeed, as in Experiment 1, when T2 was presented outside the $\mathrm{AB}$, there was a large negative deflection in the difference wave, but when $\mathrm{T} 2$ was presented during the $\mathrm{AB}$ there was not. One-sample $t$ tests performed on the mean N400 amplitude at the 320-msec lag revealed that the magnitude of the $\mathrm{N} 400$ during the $\mathrm{AB}$ was not significantly different than zero in both the arrows and equals conditions [arrows: $t(9)=0.46$, $p>.65$; equals: $t(9)=0.73, p>.48$ ]

The purpose of Experiment 2 was to determine whether a zoomed attentional spotlight caused the suppressed N400 observed in the high-load condition of Experiment 1 and to isolate the source of interference caused by the load manipulation in Experiment 1. The results of Experiment 2 clearly demonstrate that when the $\mathrm{T} 1$ task required attention to the entire $\mathrm{T} 1$ stimulus, the magnitude of the N400 was still reduced, thus the results of Experiment 1 cannot be accounted for by a restricted focus of spatial attention. Moreover, the fact that the N400 was suppressed equivalently in both the arrows and equals distractor conditions suggest that response-level interference is not the sole limiting factor, but rather that perceptual-level interference can constrain access to word meaning during the AB. Of course, it is noteworthy, however, that the similar pattern of N400 modulation in the arrows and equals condition was observed despite a large difference in T1 accuracy in the two conditions. This finding contrasts the results of Experiment 1, in which there was a modest difference in T1 accuracy, but a large difference in the pattern of N400 magnitude. A plausible explanation for this apparent discrepancy with Experiment 1 is that, within this given paradigm, both conditions had the
Figure 4. Results of Experiment 2. (A) Mean percentage of correct $\mathrm{T} 2$ responses as a function of T1 distractor type (arrows or equals) and T1-T2 lag (320 or $920 \mathrm{msec}$ ). (B) Mean amplitude of the $\mathrm{N} 400$ plotted as a function of $\mathrm{T} 1$ distractor type and T1-T2 lag.

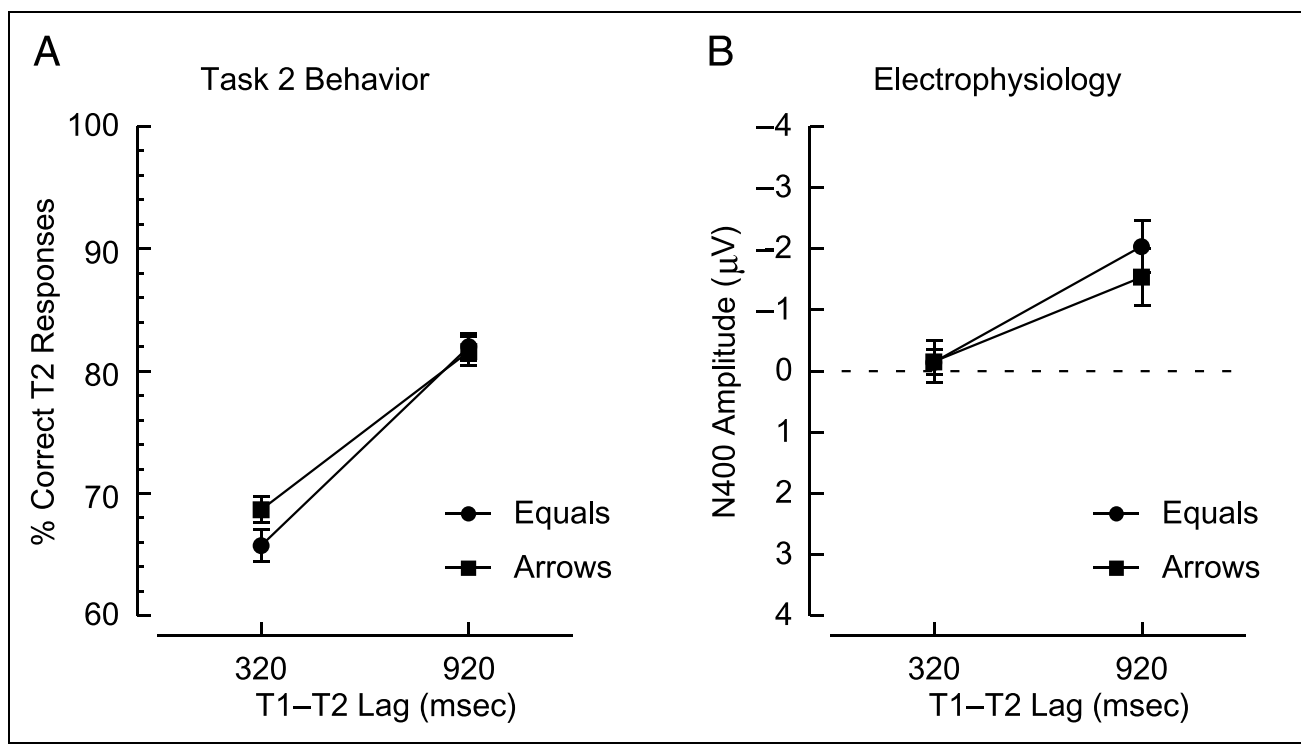


Figure 5. Average ERP unrelated - related difference waveforms at frontal $(\mathrm{Fz})$, central $(\mathrm{Cz})$, and parietal $(\mathrm{Pz})$ electrode sites for each distractor type. Solid traces are from trials in which $\mathrm{T} 2$ was presented $920 \mathrm{msec}$ after T1 and dotted traces are from trials in which $\mathrm{T} 2$ was presented 320 msec after T1 (i.e., during the $\mathrm{AB}$ ).

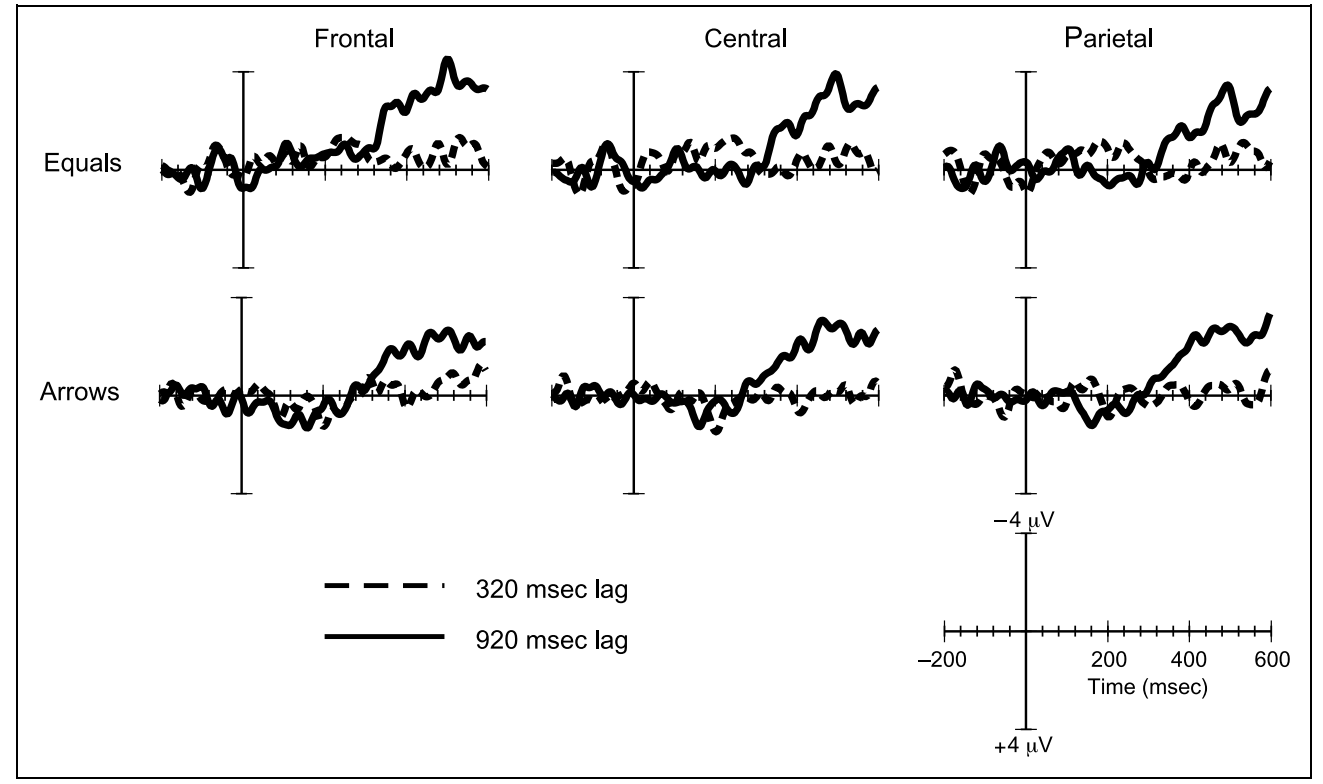

maximum level of impact on the system. Thus, despite the lower level of performance in the "arrows" condition, the magnitude of the N400 could not be suppressed further. The critical result for the present purpose, however, is that in the equals condition, where the distractors did not map onto a competing target response, there was a complete attenuation of the N400 during the $\mathrm{AB}$ supporting the conclusion that perceptual load reduces the likelihood that semantic processing will occur during the $\mathrm{AB}$.

A comparison of the magnitude of the $\mathrm{N} 400$ between Experiments 1 and 2 provides further support for the conclusion that perceptual load reduces semantic processing during the $\mathrm{AB}$. Specifically, according to the load hypothesis, the key factor in determining the amount of perceptual load is the number of items that need to be identified to perform a task. This interpretation of load predicts that the magnitude of the N400 should be larger in the high-load condition of Experiment 1 , where only a single arrow needed to be identified, compared to Experiment 2, where two arrows required identification. An independent-samples $t$ test on the magnitude of the $\mathrm{N} 400$ in the high-load conditions at the 920-msec lag shown in Figures 2 and 4 (920 msec was chosen as a baseline level of semantic processing) revealed that the $\mathrm{N} 400$ in Experiment 1 was significantly larger than the N400 in Experiment 2 $[t(20)=3.13, p<.006, S E M=0.53]$. Thus, the results of the present experiment and those of Experiment 1 support the conclusion that increased T1 perceptual load causes a reduction of semantic processing during the $\mathrm{AB}$.

\section{GENERAL DISCUSSION}

The purpose of the present work was to investigate the influence of T1 task load on semantic processing during the AB. Two experiments were presented in which semantic processing during the $\mathrm{AB}$ was indexed by measuring the N400 ERP component evoked by T2. The results of Experiment 1 demonstrated that under conditions of high T1-load, the magnitude of the N400 can be completely suppressed, while replicating previous studies showing that the magnitude of the N400 is not suppressed during the AB (Rolke et al., 2001; Luck et al., 1996) under conditions of low T1-load. The results of Experiment 2 replicated the high-load condition of Experiment 1 using a T1 flanker task that required attention to the entire stimulus and that did not contain response conflict. Together, these results provide strong support for the hypothesis that concurrent task demands imposed by the T1 task limit access to word meaning during the $\mathrm{AB}$.

The present results are consistent with a growing number of studies that suggest that postperceptual processing of $\mathrm{T} 2$ does not always occur during the $\mathrm{AB}$. For example, a series of very recent ERP studies suggest that the $\mathrm{AB}$ modulates processing stages prior to semantic access (Dell'Acqua, Sessa, Jolicoeur, \& Robitaille, 2006; Jolicoeur, Sessa, \& Dell'Acqua, 2006; Jolicoeur, Sessa, Dell'Acqua, \& Robitaille, 2006). These studies focused on the N2pc (N2 posterior contralateral) ERP component, which is thought to reflect processes involved in the allocation of perceptual processing resources to facilitate selection of a target from amongst distractors (e.g., Woodman \& Luck, 1999; Eimer, 1996; Luck \& Hillyard, 1994). Jolicoeur, Dell'Acqua, and their colleagues (Dell'Acqua et al., 2006; Jolicoeur, Sessa, \& Dell'Acqua, 2006; Jolicoeur, Sessa, Dell'Acqua, \& Robitaille, 2006) measured the N2pc evoked by a T2 presented in the periphery along with simultaneously presented distractors. These investigators found that the N2pc was completely suppressed during the $\mathrm{AB}$. Because the $\mathrm{N} 2 \mathrm{pc}$ is thought to reflect 
relatively early stages of processing, the attenuation of the $\mathrm{N} 2 \mathrm{pc}$ component during the $\mathrm{AB}$ suggests that, under some conditions, perceptual-level processing can be compromised during the $\mathrm{AB}$. Moreover, the present work converges with studies of spatial attention that have demonstrated that increased perceptual load causes reduced processing of task-irrelevant information (e.g., Pessoa et al., 2002; Handy et al., 2001; Lavie, 1995; Lavie \& Tsal, 1994). The influence of load on the extent to which information is processed to a postperceptual level has been explained by the load theory of selective attention (e.g., Lavie 2005). This theory assumes that the perceptual system devotes all of its available resources to sensory processing. If insufficient resources are available to process all of the sensory inputs, then attention acts to divert resources to task-relevant inputs, resulting in increased selectivity and reduced influence of task-irrelevant information. If, however, the system is not overloaded, then all inputs are processed without the engagement of attention.

There are two aspects of load theory that help reconcile the present results with other findings in the literature. First and foremost, there is Luck et al.'s (1996) original finding that the $\mathrm{AB}$ does not modulate the $\mathrm{N} 400$. Based on the load hypothesis, we argue that the T1 task used by Luck et al. did not place a severe enough demand on perceptual selection processes. In Luck et al.'s paradigm, the T1 task was to indicate whether a row of seven numbers of the same value (e.g., "2222222") was odd or even and overall accuracy was $96 \%$. This task bears a remarkable degree of similarity to the present low-load task that consisted of a row of five arrows pointing in the same direction in which the overall accuracy was 98\%. Although the overall level of performance is conveniently similar in the two tasks, the overall level of performance in the high-load task of the present experiments was not that far below at 90\%. In line with load theory, we argue that the effect of load is not just an effect of general task difficulty, but rather is determined by demands required to differentiate targets from distractors or the number of different identity items that require processing (e.g., Lavie, 2005). By this definition, the present low-load task and the task originally used by Luck et al. are virtually identical, but the high-load conditions, in which the flankers required exclusion to determine the correct response or that required attention to two separate items, should increase the demands on perceptual processing.

Second, load theory also helps reconcile the present results with studies that have shown increased distractor processing during the $\mathrm{AB}$. For example, Jiang and Chun (2001) presented subjects with a flanker-type T2 stimulus and found that the amount of distractor interference during the $\mathrm{AB}$ was higher than the amount of interference observed outside the $\mathrm{AB}$. Jiang and Chun argued that the typical T1 task taxes capacity-limited later stages of processing that require active control, rather than perceptual stages of processing. In other words, in line with load theory, if the T1 task does not require all available perceptual resources, but is, nevertheless, cognitively demanding enough to occupy limited capacity processing mechanisms, processing of task-irrelevant information during the $\mathrm{AB}$ can increase because there will be enough perceptual resources available to process both $\mathrm{T} 2$ and the task-irrelevant distractors.

Although the load hypothesis provides a parsimonious account of the present data and reconciles the present results with those in the literature, it must be emphasized that it is unlikely that the $A B$ itself is determined by perceptual load only. Indeed, previous studies have demonstrated that the magnitude of the $A B$ is modulated by many factors other than perceptual load, including response-related factors (Jolicoeur, 1998, 1999), strategic factors (Shore et al., 2001), motivation (Smith, Most, Newsome, \& Zald, 2006), and learning (Maki \& Padmanabhan, 1994). Within the present context, if perceptual load was the sole determinant of the $\mathrm{AB}$, then there should have been little or no $\mathrm{AB}$ in the low-load condition of Experiment 1, but that was not the case. Although future work may show that other factors (e.g., strategic, motivational, response-related, etc.) may serve to reduce postperceptual processing during the $\mathrm{AB}$, the present results demonstrate that perceptual load is sufficient to modulate the magnitude of the $\mathrm{AB}$ and that perceptual load is sufficient to modulate the extent to which unattended information is processed to the semantic level during the AB. Critically, when the present findings are considered together with previous studies showing that the $\mathrm{AB}$ is modulated by postperceptual factors, they converge on the notion that the $\mathrm{AB}$ is not a unitary phenomenon (e.g., Kawahara, Enns, \& Di Lollo, 2006) and that it can be modulated by early-stage perceptual factors, by late-stage central capacity limitations, or by a combination of the two.

\section{Implications for Models of the AB}

A variety of theoretical accounts of the $A B$ have been proposed and each one differs in terms of the explanation of the processing limitation that results in impaired processing of T2. Despite the fundamental difference in these models in terms of the nature of the processing limitation, a common assumption is that, during the $\mathrm{AB}$, the second target is processed to a semantic level even though it cannot be reported correctly. The present finding that the N400 is reduced under conditions of high task load challenges this common assumption, but each of the models could be modified to accommodate the present results. For instance, several models explain the $\mathrm{AB}$ as a capacity or resource limitation within the context of a two-stage framework. This group of models includes the two-stage model (Chun \& Potter, 1995) and its revisions (Nieuwenstein, Chun, van der Lubbe, \& Hooge, 2005; Giesbrecht \& Di Lollo, 1998), the 
interference model (Shapiro \& Raymond, 1994), the unified model (Shapiro, Arnell, \& Raymond, 1997), the hybrid model (Vogel et al., 1998), and the short-term consolidation model (Jolicoeur, 1999). Within each mod$\mathrm{el}$, incoming sensory information is handled by highcapacity processor that can fully analyze potential targets to the level of meaning. The $\mathrm{AB}$ occurs because stages of processing that are responsible for encoding potential targets into a more durable form for conscious report are limited in capacity. Thus, if T2 is presented while these later stages are busy processing T1, T2 is delayed and is vulnerable to interference from subsequent stimuli (e.g., the T2 mask; Giesbrecht \& Di Lollo, 1998). Within this framework, semantic processing of the second target is preserved during the $\mathrm{AB}$ because the highcapacity processor fully analyzes information in parallel with the operation of later stages of processing. These models could accommodate the present findings if it is assumed that the increased perceptual load can exceed the resources of the initial high-capacity processing stage. For example, if the capacity of these early stages is exceeded, then a second bottleneck would arise in the processing stream, preventing postperceptual processing of T2. In other words, as discussed above, the $A B$ could occur if perceptual processing capacity is exceeded, if postperceptual processing resources are exceeded, or if both are exceeded.

Other models explain the $\mathrm{AB}$ not as a resource limitation, but as failure of preparing the system for new inputs (Nieuwenstein \& Potter, 2006; Olivers \& Watson, 2006; Di Lollo et al., 2005; Raymond, 2003). According to one of these models, the $\mathrm{AB}$ reflects a temporary loss of control over endogenous attentional systems (Kawahara et al., 2006; Di Lollo et al., 2005; Visser, Bischof, \& Di Lollo, 1999). These endogenous systems are required to maintain input filters that match the defining characteristics of the target and to dynamically reconfigure the filters for new input once a target is detected. These control systems, however, are also required to completely process the first target. Although endogenous control systems are processing the first target, the input filters are reset by any distracting information presented between the first and second targets (e.g., the mask) and cannot be optimally configured for the second target. According to this model, any manipulation that changes the efficiency of operation of attentional control systems would modulate the $\mathrm{AB}$. Usually, this function is served by the post-T1 distractors, however, within the context of the present paradigm, the high-load stimuli could place a higher demand on voluntary selection processes that are required to reconfigure the information processing system for $\mathrm{T} 2$, as a result, T2 is not selected. Under conditions of low load, however, the attentional mechanisms required to reconfigure the system for the upcoming second target can do so on a larger proportion of the trials or to the extent that semantic information can be processed.
Other recent models also claim that selection of T1 compromises selection of T2. For instance, Olivers and Watson (2006) propose that the mechanisms that govern T2 selection from among a temporal sequence of distractors within the $\mathrm{AB}$ are the same as those that govern selection of a target from simultaneously presented distractors. According to this model, selection of T1 entails actively inhibiting subsequent information. Because of this model's reliance on a generalized selection failure that applies in both the temporal and spatial domain, it could account for the present results in a manner that parallels the load hypothesis. Recent accounts on the basis of object file theory (Kahneman \& Treisman, 1984) posit that the $\mathrm{AB}$ is caused by failure to instantiate an accurate object file for T2 (Raymond, 2003). According to this account, increasing the perceptual load of T1 would prevent the accurate creation of object file representation for T2. Critically, these object files are required for postperceptual processing, thus if an accurate $\mathrm{T} 2$ object file does not exist, then postperceptual processing will be impaired.

To summarize, the finding that semantic processing during the $\mathrm{AB}$ is attenuated by increased perceptual load challenges the common theoretical assumption that all information presented during the $\mathrm{AB}$ is processed to a postperceptual level. However, because each model of the $\mathrm{AB}$ can be modified to accommodate the present findings, the primary implication of the present work is to more completely specify the models rather than to discriminate between them.

\section{Concluding Remarks}

The finding that the N400 is suppressed under conditions of high load, but not under conditions of low load, supports the conclusion that, under some conditions, perceptual-level selection can occur, whereas under other conditions, selection is postperceptual. Although these results are incompatible with traditional early (Broadbent, 1958, 1971) and late selection views (Deutsch \& Deutsch, 1963), the present results are compatible with studies showing that attention can operate at both perceptual and postperceptual stages of processing (Vogel et al., 2005; Lavie et al., 2004; Yi, Woodman, Widdlers, Marois, \& Chun, 2004; Lavie \& Tsal, 1994). Consistent with this idea are functional neuroimaging and neurophysiological studies showing attentional influences at almost every stage of visual processing, from high-order association areas to the lateral geniculate nucleus (Moore \& Fallah, 2004; Astafiev et al., 2003; Noesselt et al., 2002; O'Connor, Fukui, Pinsk, \& Kastner, 2002; Hopfinger, Buonocore, \& Mangun, 2000; Chelazzi, Miller, Duncan, \& Desimone, 1993; Corbetta et al., 1990). This body of work suggests that visual attention is not fixed at either early or late stages of processing, but rather that attention is a multilevel selection process that can change flexibly depending on 
concurrent task demands and behavioral goals (Lavie, 2005; Vogel et al., 2005; Kastner \& Pinsk, 2004; Lavie et al., 2004; Yi et al., 2004; Lavie \& Tsal, 1994). Whereas much of the previous work has demonstrated how concurrent task demands modulate the selectivity of attention over space, the present work demonstrates that concurrent task demands can also change the selectivity of attention over time.

\section{Acknowledgments}

Support for this work was provided by NIH grant R03MH070638. We thank Edward K. Vogel and two anonymous reviewers for their insightful and constructive comments on an earlier version of this manuscript.

Reprint requests should be sent to Barry Giesbrecht, Department of Psychology, University of California, Santa Barbara, CA 93106, or via e-mail: giesbrecht@psych.ucsb.edu.

\section{Notes}

1. There are two types of paradigms used to study the AB. In one, the targets are displayed within a rapid serial visual presentation stream of distractors in which the stimulus onset asynchrony between all items is the same, which renders the duration of $\mathrm{T} 1$ and $\mathrm{T} 2$ the same. In the second, only the two targets and masks are presented (Duncan et al., 1994). Although in the second paradigm the durations of the two targets are often the same, the lack of the distractor stream allows the experimenter to tailor the durations for optimal performance of each target more readily. The different durations were used because pilot testing revealed that a longer duration $\mathrm{T} 2$ was too easy (i.e., no $\mathrm{AB}$ ) and a shorter duration T1 task was too difficult.

2. It is typical in studies of the $\mathrm{AB}$ to analyze $\mathrm{T} 2$ performance and T2-evoked ERPs only on trials in which T1 was correctly reported. The rationale is that if subjects reported T1 correctly, then they were attending to the task, but one cannot be sure what they were doing on tasks in which T1 was not reported correctly. In the present study, however, we decided a priori to include both T1-correct and T1-incorrect trials. There were two reasons on which we based our decision. First, because the difficulty of the first target task was the primary manipulation, subjects could very conceivably follow task instructions, but still report $\mathrm{T} 1$ incorrectly. Thus, excluding $\mathrm{T} 1$ based on accuracy could potentially exclude trials in which subjects were performing the task appropriately. Second, we were concerned that excluding trials based on accuracy along with trials rejected due to artifacts detected in the ERP would reduce our signal-to-noise ratio for the ERP analyses. As a result, the behavioral and ERP analyses reported here include both T1correct and T1-incorrect trials. Additional analyses that included only T1-accurate trials were performed and the results were consistent with those reported here.

\section{REFERENCES}

Astafiev, S. V., Shulman, G. L., Stanley, C. M., Snyder, A. Z., Van Essen, D. C., \& Corbetta, M. (2003). Functional organization of human intraparietal and frontal cortex for attending, looking, and pointing. Journal of Neuroscience, 23, 4689-4699.

Brainard, D. H. (1997). The psychophysics toolbox. Spatial Vision, 10, 433-436.
Broadbent, D. E. (1958). Perception and communication. London: Pergamon.

Broadbent, D. E. (1971). Decision and stress. London: Academic Press.

Chelazzi, L., Miller, E. K., Duncan, J., \& Desimone, R. (1993). A neural basis for visual search in inferior temporal cortex. Nature, 363, 345-347.

Chun, M. M., \& Potter, M. C. (1995). A two-stage model for multiple target detection in rapid serial visual presentation. Journal of Experimental Psychology: Human Perception and Performance, 21, 109-127.

Corbetta, M., Miezin, F. M., Dobmeyer, S., Shulman, G. L., \& Petersen, S. E. (1990). Attentional modulation of neural processing of shape, color, and velocity in humans. Science, 248, 1556-1559.

Dell'Acqua, R., Sessa, P., Jolicoeur, P., \& Robitaille, N. (2006). Spatial attention freezes during the attention blink. Psychophysiology, 43, 394-400.

Deutsch, J. A., \& Deutsch, D. (1963). Attention: Some theoretical considerations. Psychological Review, 70, 80-90.

Di Lollo, V., Kawahara, J., Shahab Ghorashi, S. M., \& Enns, J. T. (2005). The attentional blink: Resource depletion or temporary loss of control. Psychological Research, 69, 191-200.

Duncan, J., Ward, R., \& Shapiro, K. (1994). Direct measurement of attentional dwell time in human vision. Nature, 369, 313-315.

Eimer, M. (1996). The N2pc component as an indicator of attentional selectivity. Electroencephalography and Clinical Neurophysiology, 99, 225-234.

Eriksen, B. A., \& Eriksen, C. W. (1974). Effects of noise letters upon the identification of a target letter in a nonsearch task. Perception \& Psychophysics, 16, 143-149.

Eriksen, C. W., \& Hoffman, J. E. (1973). The extent of processing of noise elements during selective encoding from visual displays. Perception \& Psychophysics, 14, 155-160.

Eriksen, C. W., \& St. James, J. D. (1986). Visual attention within and around the field of focal attention: A zoom lens model. Perception \& Psychophysics, 40, 225-240.

Giesbrecht, B., Camblin, C. C., \& Swaab, T. Y. (2004). Separable effects of semantic priming and imageability on word processing in human cortex. Cerebral Cortex, 14, 521-529.

Giesbrecht, B., \& Di Lollo, V. (1998). Beyond the attentional blink: Visual masking by object substitution. Journal of Experimental Psychology: Human Perception and Performance, 24, 1454-1466.

Giesbrecht, B., \& Sy, J. L. (2006). Electrophysiological evidence for modulation of semantic processing during the attentional blink [Abstract]. Journal of Vision, 6, 1015.

Handy, T. C., Soltani, M., \& Mangun, G. R. (2001). Perceptual load and visuocortical processing: Event-related potentials reveal sensory-level selection. Psychological Science, 12, 213-218.

Heinze, H. J., Mangun, G. R., Burchert, W., Hinrichs, H., Scholz, M., Muente, T. F., et al. (1994). Combining spatial and temporal imaging of brain activity during visual selective attention in humans. Nature, 372, 543-546.

Hillyard, S. A., Hink, R. F., Schwent, V. L., \& Picton, T. W. (1973). Electrical signs of selective attention in the human brain. Science, 182, 177-180.

Hopfinger, J. B., Buonocore, M. H., \& Mangun, G. R. (2000). The neural mechanisms of top-down attentional control. Nature Neuroscience, 3, 284-291.

Jiang, Y., \& Chun, M. M. (2001). The influence of temporal selection on spatial selection and distractor interference: An attentional blink study. Journal of Experimental Psychology: Human Perception and Performance, 27, 664-679. 
Jolicoeur, P. (1998). Modulation of the attentional blink by on-line response selection: Evidence from speeded and unspeeded task decisions. Memory \& Cognition, 26, 1014-1032.

Jolicoeur, P. (1999). Concurrent response-selection demands modulate the attentional blink. Journal of Experimental Psychology: Human Perception and Performance, 25, 1097-1113.

Jolicoeur, P., Sessa, P., \& Dell'Acqua, R. (2006). On the control of visual spatial attention: Evidence from human electrophysiology. Psychological Research, 70, 414-424.

Jolicoeur, P., Sessa, P., Dell'Acqua, R., \& Robitaille, N. (2006). Attentional control and capture in the attentional blink paradigm: Evidence from human electrophysiology. European Journal of Cognitive Psychology, 18, 560-578.

Kahneman, D., \& Treisman, A. (1984). Changing views of attention and automaticity. In R. Parasuraman \& D. R. Davies (Eds.), Varieties of attention. New York: Academic Press.

Kastner, S., \& Pinsk, M. A. (2004). Visual attention as a multilevel selection process. Cognitive, Affective, $\mathcal{G}$ Behavioral Neuroscience, 4, 483-500.

Kawahara, J., Enns, J. T., \& Di Lollo, V. (2006). The attentional blink is not a unitary phenomenon. Psychological Research, 70, 405-413.

Kutas, M., \& Hillyard, S. A. (1980). Reading senseless sentences: Brain potentials reflect semantic incongruity. Science, 207, 203-205.

Lavie, N. (1995). Perceptual load as a necessary condition for selective attention. Journal of Experimental Psychology: Human Perception and Performance, 23, 451-468.

Lavie, N. (2005). Distracted and confused?: Selective attention under load. Trends in Cognitive Sciences, 9, 75-82.

Lavie, N., Hirst, A., de Fockert, J. W., \& Viding, E. (2004). Load theory of selective attention and cognitive control. Journal of Experimental Psychology: General, 133, 339-354.

Lavie, N., \& Tsal, Y. (1994). Perceptual load as a major determinant of the locus of selection in visual attention. Perception \& Psychophysics, 56, 183-197.

Loftus, G. R., \& Masson, M. E. J. (1994). Using confidence intervals in within-subjects designs. Psychonomic Bulletin E Review, 1, 476-490.

Luck, S. J., \& Hillyard, S. A. (1994). Spatial filtering during visual search: Evidence from human electrophysiology. Journal of Experimental Psychology: Human Perception and Performance, 20, 1000-1014.

Luck, S. J., Vogel, E. K., \& Shapiro, K. L. (1996). Word meanings can be accessed but not reported during the attentional blink. Nature, 383, 616-618.

Mack, A., Pappas, Z., Silverman, M., \& Gay, R. (2002). What we see: Inattention and the capture of attention by meaning. Consciousness and Cognition, 11, 488-506.

Maki, W. S., Frigen, K., \& Paulson, K. (1997). Associative priming by targets and distractors during rapid serial visual presentation: Does word meaning survive the attentional blink? Journal of Experimental Psychology: Human Perception and Performance, 23, 1014-1034.

Maki, W. S., \& Padmanabhan, G. (1994). Transient suppression of processing during rapid serial visual presentation: Acquired distinctiveness of probes modulates the attentional blink. Psychonomic Bulletin \& Review, 1, 499-504.

Mangun, G. R., \& Hillyard, S. A. (1991). Modulation of sensory-evoked brain potentials provide evidence for changes in perceptual processing during visual-spatial priming. Journal of Experimental Psychology: Human Perception and Performance, 17, 1057-1074.

Marois, R., Yi, D.-J., \& Chun, M. M. (2004). The neural fate of consciously perceived and missed events in the attentional blink. Neuron, 41, 465-472.
McCarthy, G., \& Nobre, A. C. (1993). Modulation of semantic processing by spatial selective attention. Electroencephalography and Clinical Neurophysiology, 88, 210-219.

Moore, T., \& Fallah, M. (2004). Microstimulation of the frontal eye field and its effects on covert spatial attention. Journal of Neurophysiology, 9, 152-162.

Nieuwenstein, M. R., Chun, M. M., van der Lubbe, R. H. J., \& Hooge, I. T. C. (2005). Delayed attentional engagement in the attentional blink. Journal of Experimental Psychology: Human Perception and Performance, 31, 1463-1475.

Nieuwenstein, M. R., \& Potter, M. C. (2006). Temporal limits of selection and memory encoding: A comparison of whole versus partial report in rapid serial visual presentation. Psychological Science, 17, 471-475.

Noesselt, T., Hillyard, S. A., Woldorff, M. G., Schoenfeld, A., Hagner, T., Jäncke, L., et al. (2002). Delayed striate cortical activation during spatial attention. Neuron, 35, 575-587.

O'Connor, D. H., Fukui, M. M., Pinsk, M. A., \& Kastner, S. (2002). Attention modulates responses in the human lateral geniculate nucleus. Nature Neuroscience, 5, 1203-1209.

Olivers, C. N. L., \& Watson, D. G. (2006). Input control processes in rapid serial visual presentations: Target selection and distractor inhibition. Journal of Experimental Psychology: Human Perception and Performance, 32, 1083-1092.

Pessoa, L., McKenna, M., Guitierrez, E., \& Ungerleider, L. G. (2002). Neural processing of emotional faces requires attention. Proceedings of the National Academy of Sciences, U.S.A., 99, 11458-11463.

Posner, M. I. (1980). Orienting of attention. Quarterly Journal of Experimental Psychology, 32, 3-25.

Postman, L. J., \& Keppel, G. (1970). Norms of word association. New York: Academic Press.

Potter, M. C., Dell'Acqua, R., Pesciarelli, F., Job, R., Peressotti, F., \& O'Connor, D. H. (2005). Bidirectional semantic priming in the attentional blink. Psychonomic Bulletin \& Review, 12, 460-465.

Raymond, J. E. (2003). New objects, not new features, trigger the attentional blink. Psychological Science, 14, 54-59.

Raymond, J. E., Shapiro, K. L., \& Arnell, K. M. (1992). Temporary suppression of visual processing in an RSVP task: An attentional blink? Journal of Experimental Psychology: Human Perception and Performance, 18, 849-860.

Raymond, J. E., Shapiro, K. L., \& Arnell, K. M. (1995). Similarity determines the attentional blink. Journal of Experimental Psychology: Human Perception and Performance, 21, 653-662.

Rees, G., Frith, C. D., \& Lavie, N. (1997). Modulating irrelevant motion perception by varying attentional load in an unrelated task. Science, 278, 1616-1619.

Rolke, B., Heil, M., Streb, J., \& Henninghausen, E. (2001). Missed prime words within the attentional blink evoke an N400 semantic priming effect. Psychophysiology, 38, 165-174.

Sergent, C., Baillet, S., \& Dehaene, S. (2005). Timing of the brain events underlying access to consciousness during the attentional blink. Nature Neuroscience, 8, 1391-1400.

Shapiro, K., Driver, J., Ward, R., \& Sorensen, R. E. (1997). Priming from the attentional blink: A failure to extract visual tokens but not visual types. Psychological Science, 8, 95-100.

Shapiro, K. L., Arnell, K. M., \& Raymond, J. E. (1997). The attentional blink. Trends in Cognitive Sciences, 1, 291-296.

Shapiro, K. L., Caldwell, J., \& Sorensen, R. E. (1997). Personal names and the attentional blink: A visual "cocktail party" effect. Journal of Experimental Psychology: Human Perception and Performance, 23, 504-514. 
Shapiro, K. L., \& Raymond, J. E. (1994). Temporal allocation of visual attention: Inhibition or interference? In D. Dagenbach \& T. H. Carr (Eds.), Inbibitory processes in attention, memory, and language. San Diego: Academic Press.

Shapiro, K. L., Raymond, J. E., \& Arnell, K. M. (1994). Attention to visual pattern information produces the attentional blink in rapid serial visual presentation. Journal of Experimental Psychology: Human Perception and Performance, 20, 357-371.

Shore, D. I., McLaughlin, E. N., \& Klein, R. M. (2001). Modulation of the attentional blink by differential resource allocation. Canadian Journal of Experimental Psychology, 55, 318-324.

Smith, S. D., Most, S. B., Newsome, L. A., \& Zald, D. H. (2006). An emotion-induced attentional blink elicited by aversively conditioned stimuli. Emotion, 6, 523-527.

Van Voorhis, S. T., \& Hillyard, S. A. (1977). Visual evoked potentials and selective attention to points in space. Perception \& Psychophysics, 22, 54-62.
Visser, T. A. W., Bischof, W. F., \& Di Lollo, V. (1999). Attentional switching in spatial and nonspatial domains: Evidence from the attentional blink. Psychological Bulletin, 125, 458-469.

Vogel, E. K., Luck, S. J., \& Shapiro, K. L. (1998).

Electrophysiological evidence for a post-perceptual locus of suppression during the attentional blink. Journal of Experimental Psychology: Human Perception and Performance, 24, 1656-1674.

Vogel, E. K., Woodman, G. F., \& Luck, S. J. (2005). Pushing around the locus of selection: Evidence for the flexible-selection hypothesis. Journal of Cognitive Neuroscience, 17, 1907-1922.

Woodman, G. F., \& Luck, S. J. (1999). Electrophysiological measurement of rapid shifts of attention during visual search. Nature, 400, 867-869.

Yi, D.-J., Woodman, G. F., Widdlers, D., Marois, R., \& Chun, M. M. (2004). Neural fate of ignored stimuli: Dissociable effects of perceptual and working memory load. Nature Neuroscience, 7, 992-996. 